Acta regionalia et environmentalica 2

Nitra, Slovaca Universitas Agriculturae Nitriae, 2013, p. 38-41

\title{
LIFE CYCLE OF MISCANTHUS × GIGANTEUS (GREEF ET DEU) GROWN IN SOUTHWESTERN SLOVAKIA CONDITIONS
}

\author{
Zuzana JUREKOVÁ, Marián KOTRLA, Žaneta PAUKOVÁ \\ Slovak University of Agriculture in Nitra, Slovakia
}

\begin{abstract}
The paper presented herein evaluates the life cycle of perennial grass Miscanthus $\times$ giganteus (Greef et Deu), a promising secondgeneration energy crop. The plants of the three-year-old stand (2010-2012) grown on arable land in southwestern Slovakia consisted only from vegetative organs in the first and second year of the cultivation (vegetative phase and phase of stem elongation). In the third growing year (2012), a part of the plants entered the reproductive phase and the phase of seed maturation. From August to September, $7-8 \%$ of stems in clumps flowered. Vegetative and productive shoots were identified in the clumps. The ripe seeds after harvesting (126 days) did not germinate at standard germination conditions. The analysis of the characteristics of leaf quantity and location of stomata pointed to the impact of individual life cycle of leaves on the number of stomata. The number of stomata was lower in juvenile leaves compared with mature leaves. Statistically highly significant dependence of leaf surface and leaf age on the number of stomata was found.
\end{abstract}

Keywords: Miscanthus, life cycle, stomata, seed germination

Biomass production on agricultural land is a significant contribution to the balance of renewable energy sources. Current development of production and biomass use shows that fast growing plants and trees have a growing tendency and become an important part of agriculture in Europe and worldwide (Dražič and Milovanovič, 2010).

The most commonly grown and commercially used are the trees of genus Salix and perennial grasses of genus Miscanthus. They are characterized by high biomass production even on less valuable soils and variable environmental conditions. Their production potential is high for 15 to 20 years (Karp and Shield, 2008; FAO, 2008). Stands of the so called energy trees and plants (especially Salix and Miscanthus) contribute to the mitigation of climate change and energy security.

Creation and distribution of matter into the organs of perennial grasses is closely related to the morphology and architecture of the species, which can be characterized at different hierarchical levels, for example individual shoots and their growth units - phytomers, phytomer structures, such as nodes, inernodes, leaf sheath, apical meristem (Moore and Moser, 1995), leaves and their structures. Knowledge of the patterns of their growth, development and life cycle is important from the point of view of the potential rate of biomass production, cultivation management, application of nutrients and herbicides, defoliation after a disturbance, subsequent regeneration, etc.

The paper presents results of the life cycle of Miscanthus $\times$ giganteus (Greef et Deu) grown on agricultural land in conditions of southern Slovakia. The analyses were made on three hierarchical levels: on the clump level, individual stems, and leaves. Stomatal density and their location were observed on the leaf skin depending on the growth stage of the leaf. The results were compared with stomatal density and their localization in the leaf skin of Miscanthus sinensis (Tatai).
The aim was to characterize vegetative and reproductive growth phase in the growing years of 2011 and 2012, leaf characteristics in terms of differences in stomatal density, flowering, ripening and seed germination.

\section{Material and methods}

The research was carried out on the field trial base of the University Farm Holding of Slovak University of Agriculture in Kolíňany. The research station is located $13 \mathrm{~km}$ from Nitra $\left(48^{\circ} 21^{\prime} 20^{\prime \prime} \mathrm{N}, 18^{\circ} 12^{\prime} 23^{\prime \prime} \mathrm{E}\right)$. It belongs to the cadastral area of Kolínany. The code of the soil quality defined by BSEU is 0111002. The main soil type is gley fluvisol, in terms of grain structure it belongs to moderately heavy soils. In terms of exposure, this area is plain without an expression of surface erosion $\left(0^{\circ}\right.$ to $\left.1^{\circ}\right)$. Soils are deep $(60 \mathrm{~cm}$ or more), without skeleton.

\section{Characteristics of the studied material}

Two genotypes were used: Miscantus $\times$ giganteus and Miscanthus sinensis (Tatai). Miscantus $\times$ giganteus (Greef and Deuter, 1993) is a vital triploid hybrid (57 chromosomes). The planting material consisted of rhizomes from company Hannes Stelzhammer, Austria. Miscanthus sinensis (Tatai) is also a triploid hybrid ( 57 chromosomes). It was bred by crosspollination of Miscanthus sinensis genotypes. The planting material consisted of seedlings grown in vitro in Power- $\mathrm{H}$ Kft, Hungary. Before the planting, the seedlings were planted individually in rooting containers with soil substrate (Jureková et al., 2012). The stand structure of both genotypes was determined by the number of individuals per $\mathrm{m}^{2}$.

The number of stems per individual plants was determined by counting of the stems in the clump during the growing seasons of 2011 and 2012. The number of 
leaves in the clump and number of leaves on the stem was observed in the second and third year after planting (2011 and 2012). Based on that, we determined the senescence of leaves on the stem. The statistical evaluation of the number of stems and leaves on the stems and clumps was carried out in statistical program STATISTICA 10, using single-factor analysis of variance (ANOVA) and Scheffe test.

The life cycle of Miscanthus was characterized by the growth and development of stems, which was divided by Moore and Moser (1995) into four primary growth stages: $1^{\text {st }}$ Vegetative phase - the phase of leaf growth, $2^{\text {nd }}$ Elongation phase - stem elongation, $3^{\text {rd }}$ Reproductive phase - development of inflorescences and $4^{\text {th }}$ Phase of formation and maturation of seeds. The individual phases correspond with specific morphological status.

Seed germination. Seeds from the 2012 production of genotype Miscanthus $\times$ giganteus and Miscanthus sinensis (Tatai) were transferred in panicles ( 40 pcs) to the laboratory conditions on $14^{\text {th }}$ of November 2012. The material was left to dry out at room temperature and stored under the same conditions. After 126 days, the average seed sample was tested for germination. The test was carried out in Petri dishes (12 cm in diameter) on two sheets of filter paper saturated with distilled water. The water was supplemented daily in the same volume. Each sample consisted of 50 seeds. The Petri dishes were stored under laboratory conditions in the light and/or in the dark. The room temperature was $24{ }^{\circ} \mathrm{C}$. During the test, which lasted 10 days, the seeds were inspected daily and assessed visually and/or under binocular magnifier.

Stomatal density. Dynamics of stomatal density on the leaves was determined by non-destructive method in three randomly selected clumps for each genotype in 2012. The analysis was performed on designated stem on the juvenile, adult and senescent leaf (fifth leaf) with southeast exposure by micro-relief method (Pazourek, 1963). The samples were collected in the apical, middle and basal leaf part outside of the main vein on the adaxial (top) and abaxial (bottom) skin surface. The evaluation of preparations was carried out by optical microscope Axiostar plus, Carl Zeiss lens, CP-Achromat $40 \times / 0.65,10 \times$ eyepiece PI/18, Canon Utilities software Zoom Browser EX 4.6 and hardware Acer Travel Mate 4600, Canon Power Shot A 95. Statistical significance of differences was evaluated by LSD-test in software Statgraphic Plus.

\section{Results and discussion}

The morphological structure of perennial grasses, including species of the genus Miscanthus has a modular structure composed of structural subunits - modules. According to White (1984), Briske (1991) and Moore and Moser (1995), perennial grasses represent a set of shoots, which grow from rhizome buds and have the same genetic characteristics as the primary stem. Morphological, growth and mass differences of individual stems are determined by the number and length of phytomers (growth units consisting of node, internodes, leaf blade, leaf sheath and apical meristem (Briske, 1991). Growth units are sequentially organized into the complex structure of the stem, which represent the highest organizational level. The number of vivid stems per clump (and/or per unit area) is determined by the rate of their growth during the growing season and is related to the life cycle. The growth of stems is defined as a result of the interaction between physiological processes and environmental factors that affect them. For example, in perennial grasses formed by big amount of ontogenetically different stems, each stem is in a different growth and developmental status. Additionally, individual stems differ from each other by different growth units (phytomers).

The amount of functional stems and length of their life activity determine a potential of the species for biomass production and are dependent on the availability of resources and current environmental conditions. Therefore, it is important to study the growth process on the basis of physiological processes over time.

The results of our analyses in the growing conditions of 2011 and 2012 confirmed that the vegetative growth phase of Miscanthus $\times$ giganteus takes place in the spring and summer. The average number of stems per clump was 17.37 in the first year after the stand establishment (second growing year - 2011). The maximum number of leaves in the clump was 215.37. Vegetative growth phase and stem elongation continued into the second decade of August, when the average number of leaves per stem was 10.58 . By the end of the growing season (October), the average number of functional (green) leaves per stem was 9.2.

The vegetative growth was subject to seasonal changes also in the three-year old stand (2012). The growth of stems and leaves began in April, when the average daily air

Table 1 Single-factor analysis of variance (ANOVA) and Scheffe test of the average number of shoots and the average number of leaves in the clumps of Miscanthus $\times$ giganteus

\begin{tabular}{|l||c|c|c|c|c|}
\hline \multicolumn{7}{|c|}{ Analysis of variance $\boldsymbol{p}<\mathbf{0 . 0 5 0 0 0}$} \\
\hline & Sum of squares & Degree of freedom & Mean squares & F & p \\
\hline \hline Number of stems & 11002.34 & 1 & 11002.34 & 78.90199 & 0.000001 \\
\hline Number of leaves in a clump & 1278735 & 1 & 1278735 & 20.23367 & 0.000729 \\
\hline
\end{tabular}

\begin{tabular}{|l||c|c|}
\hline \multicolumn{3}{|c|}{ Scheffe test; variable: number of stems $\boldsymbol{p}<\mathbf{0 . 0 1 0 0 0}$} \\
\hline & $\{\mathbf{1}\}-\boldsymbol{M}=\mathbf{1 7 . 3 7 7}$ & $\{\mathbf{2}\}-\boldsymbol{M}=\mathbf{7 3 . 4 4 4}$ \\
\hline $2011\{1\}$ & & 0.000001 \\
\hline $2012\{2\}$ & 0.000001 & \\
\hline
\end{tabular}

Scheffe test; variable: number of leaves on the clump $p<0.01000$

\begin{tabular}{|l|c|c|}
\hline & $\{\mathbf{1}\}-\boldsymbol{M}=\mathbf{1 4 3 . 5 2}$ & $\{\mathbf{2}\}-\boldsymbol{M}=\mathbf{7 4 7 . 9 7}$ \\
\hline \hline $2011\{1\}$ & & 0.000729 \\
\hline $2012\{2\}$ & 0.000729 & \\
\hline
\end{tabular}



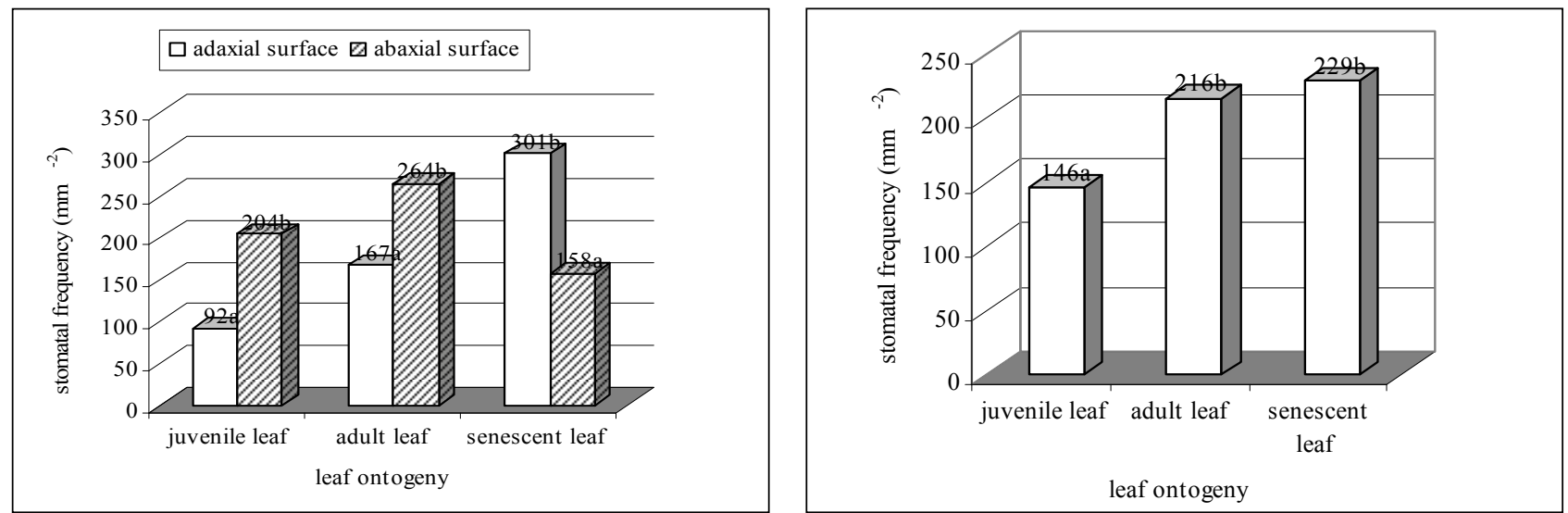

Figure 1 Statistical evaluation of significant differences in the number of stomata per $\mathrm{mm}^{2}$ of the adaxial surface and abaxial surface, depending on the leaf ontogeny. Values with different letters $(a, b)$ in columns indicate statistically significant difference according to LSD test $(P<0.05)$

temperature was $10^{\circ} \mathrm{C}$. The stem formation was intense. In comparison with 2011 , their number increased by $323 \%$. The maximum number of stems (on average 96.39 stems per clump) was reached in June 2012. In the next period from July to October, the number of vivid functional stems gradually declined. The analysis of the number of stems and number of leaves showed evident statistically highly significant differences between the years (table 1) on the significance level $\alpha=0.05, p$-value $=0.000001$ for the average number of stems in the clump and $p=0.000729$ for the average number of leaves in the clump.

The growth and development of individual leaves and internodes, organs of photosynthetic assimilation and organic matter production took place in the vegetative growth phase. A detailed study of stomatal density was made at the leaf level in the juvenile stage, stage of maturity and senescence.

Statistically highly significant dependence of the number of stomata on genotype was confirmed (LSD $_{0.05}$ test \pm 11.02 ) in the skin of juvenile leaves (Jureková et al., 2012). No differences were found in the subsequent period. The number of stomata on leaves was statistically highly significantly affected by adaxial and abaxial skin surface of leaves $\left(\mathrm{LSD}_{0.05}\right.$ test $\pm 11.02, \pm 34.63$, and \pm 53.10 ) (Figure 1). Heterogeneity in the number of stomata between the apical and middle part of the iuvenile leaf (LSD ... test \pm 13.49 )

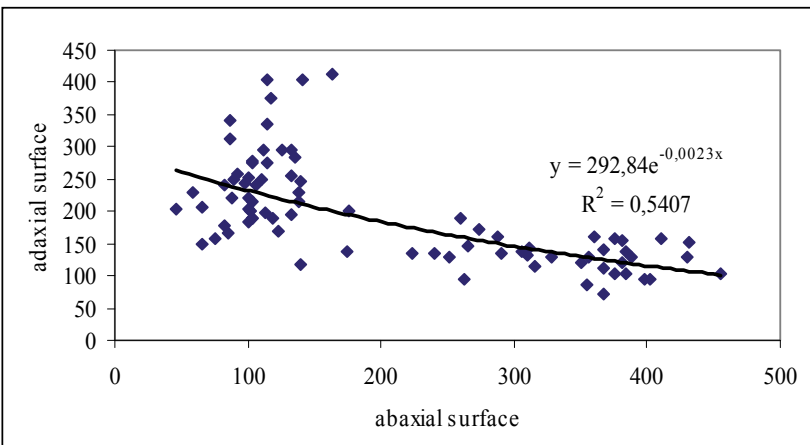

Figure 2 Exponential dependence between the number of stomata on the abaxial surface and on the adaxial surface per $\mathrm{mm}^{2}$ in the year 2012 was also confirmed in previous work (Jureková et al., 2012). The heterogeneity was also confirmed between the middle and basal part of the senescent leaf $\left(\mathrm{LSD}_{0.05}\right.$ test \pm 37.52$)$. There was no statistically significant evidence among the apical, middle and basal part of the mature leaf. Statistically significant differences in the number of leaf stomata between juvenile and adult leaves ( $\mathrm{LSD}_{0.05}$ test \pm 26.04$)$ and between juvenile and senescent leaves ( LSD $_{0.05}$ test \pm 26.04 ) were confirmed (Figure 1).

The exponential relationship between the number of stomata on the abaxial and adaxial leaf skin was observed. The value of the correlation coefficient $(0.73)$ is evaluated as very highly significant (Figure 2).

Furukawa (1992) states that the density of stomata on adaxial and abaxial leaf surface decreases with ontogenesis and position of sunflower leaves (Helianthus annuus L.) (C3 plant) grown in controlled environmental conditions. The ratio of the stomatal density on adaxial and abaxial side did not change with ontogenesis of leaves and their position on the stem. As much as $42-46 \%$ of the stomata were located on the adaxial surface. Stomatal density of Miscanthus leaves increases with leaf age, with the exception of transition of mature leaves to senescent phase on the abaxial surface. The ratio of the stomatal density on the adaxial and abaxial side changed according to the leaf age (M. $\times$ giganteus $32.6 \%, 47.9 \%$ and $66.5 \%, M$. sinensis $30.9 \%$, $28 \%$ and $63 \%$ on the adaxial side of the leaf).

There was no flowering of the studied plants observed in 2011. Therefore, the life cycle is not finished in the first year of production. It ended with the phase of the vegetative growth. According to Adati (1958) and Deuter (2000), initiation of the flowering is dependent on the origin of genotype and photoperiod. Hayashi (1979) characterized Miscanthus as apparently day-neutral in natural conditions of Japan (country of origin), blooming between September and October. In general, flowering ends in June-September in the areas with higher latitudes and between September and October in regions with lower latitudes.

The reproductive phase took place in 2012. The flowering was observed on $7-8 \%$ stems per clump. Elongation of the highest internodes (reproductive phase) and panicle formation began in August. During this period, the stems 
were already differentiated into vegetative and productive ones. The process of flowering and seed formation of Miscanthus genotypes is well studied in the field conditions, and several authors (Greef, 1995; Hotz et al., 1996; CliftonBrown et al., 2001) indicate that genotypes, which bloom later and their vegetative organs age later have an extended growing season and increased biomass production.

The phase of formation and maturation of seeds took place in September and October. Shimoda (1997) states that the seeds at higher latitudes are formed only in years with higher summer temperatures and the stand density had a significant influence (proximity of pollen sources). Miscanthus $\times$ giganteus as triploid hybrid is self-incompatible and cannot produce fertile seeds. Nevertheless, the knowledge of the size and characteristics of the seeds is considered as important in terms of dissemination of seeds and seed bank. In a laboratory experiment, we verified the seed germination of Miscanthus $\times$ giganteus and Miscanthus sinensis (Tatai) from the production of 2012. The results of the experiment were negative. The seeds of both varieties in all samples and replicates did not germinate.

\section{Conclusion}

The results of the experiments with perennial rhisomatous grass Miscanthus sinensis grown in conditions of southwestern Slovakia provide conclusions that contribute to the knowledge of the life cycle, methodology of quantitative morphology, and can be utilized in the cultivation management. The stand of Miscanthus $\times$ giganteus during the growing season of the first and second growing year consisted only of vegetative organs and remained in the vegetative and elongation growth phase. The reproductive phase and the phase of formation and maturation of seeds took place in the third growing year (2012). Altogether 7-8\% of stems flowered. It is possible to identify vegetative and productive stems in the clump. Ripe seeds stored in laboratory conditions ( 126 days) did not germinate at standard conditions of germination. Leaves have their individual life cycle during which the stomatal density changes. Juvenile leaves have lower stomatal density than mature leaves. We confirmed statistically highly significant dependence of the number of stomata on the leaf surface and age.

\section{Acknowledgment}

This work was supported by the Slovak Grant Agency for Sciences (VEGA) Grant No. 1/1220/12 and by the AgroBioTech ITMS 26220220180.

\section{References}

ADATI, S. 1958. Studies on the genus Miscanthus with special reference to the Japanese species for breeding purpose as fodder crops. In: Bulletin of the faculty of Agronomy, Mie University, 1958, 17, pp.1-112.

BRISKE, D. D. 1991. Developmental Morphology and Physiology of Grasses. In: R. K. Heitschmidt and V. W. Stuth (ed) Grazing management : An Ecological Perspectives. Timber Press Portland, OR.
CLIFTON-BROWN, J. C. et al. 2001. Performance of 15 Miscanthus Genotypes at Five Sites in Europe. In: Agronomy Journal, vol. 93, 2001, no. 5, pp. 1013-1019.

DEUTER, M. 2000. Breeding approaches to improvement of yield and quality in Miscanthus grown in Europe. In: Lewandowski, I., Clifton-Brown, J. C. (ed) European Miscanthus improovement final Report, September 2000. Stutgart, 2000, pp. 28-52.

DRAŹIĆ, G. - MILOVANOVIĆ, J. 2010. Forest lands valorization possibility throught fast growing energy crop Miscanthus giganteus cultivation. In: International scientific conference "Forest ecosystems and climate changes". Institute of Forestry Belgrade, IUFRO, EFI. Belgrade 9-10 March. Procedings, 2010, pp. 303-308.

FAO. 2008. The State of Food and Agriculture 2008. Bio-fuels Risks and Oportunities. FAO Rome, Italy, 2008, 138 p.

FURUKAWA, A. 1992. Ontogenetic changes in stomatal size and conductance of sunflowers. In Ecological research. vol. 7, 1992, no. 2, pp. 147-153. ISSN 0912-3814.

GREEF, J. M. 1995. Etablierung und Biomass ebildung von Miscanthus $\times$ giganteus. Habilitation : Universitet Kiel. Göttingen :Cuvillier Verlag. 1995, 162 p.

GREEF, J. M. - DEUTER, M. 1993. Syntaxonomy of Miscanthus $\times$ giganteus GREEF et DEU. In: Angewandte Botanik, 67, 1993, pp. 87-90.

HAYASHI, I. 1979. The autecology of some grassland species In: Ecology of Grasslands and Bamboolands in theWorld (ed Numata M), 1979, pp. 141-152.

HOTZ, A. - KUHN, W. - JODL, S. 1996. Screening of different Miscanthus cultivars in respect of yield production and usability as a raw material for energy and industry. In: Proceedings of the Ninth European Bioenergy Conference, Copenhagen, Denmark, 24-27 June 1996, New York : Pergamon, 1996, p. 523-527.

JUREKOVÁ, Z. - KOTRLA, M. - PAUKOVÁ, Ž. - PRČíK, M. 2012. The growth and yield of different Miscanthus genotypes in the conditions of south-western Slovakia. In: Acta regionalia et environmentalica, 2012, no. 2, p. 29-34. ISSN 1336-5452.

KARP, M. - SHIELD, I. 2008. Bioenergy from Plants and the Sustainable Yield Chalenge. In: New Phytologist, 2008, no. 179, pp. 15-32.

MOORE, K. J. - MOSER, L. E. 1995. Quantifying Developmental Morphology of Perennial Grasses. In: Crop Science, vol. 35, 1995. PAZOUREK, J. 1963. Studium listové epidermis mikroreliefovou metodou. In: Preslia, 35, 1963, pp. 210-216.

SHIMODA, K. 1997. Regeneration of Miscanthus sinensis in Kirigamine: temporal variation of seed production and regeneration of seed. In: Japanese Journal of Grassland Science, 1997, p. 43.

WHITE, J. 1984. Plant metamerism. In: R. Dirzo, J. Sarukhán (ed) Perspectives on plant population biology. Sinauer ASSOCIATES, Inc., Sunderland, MA, 1984.

Contact address:

prof. RNDr. Zuzana Jureková, CSc., Slovak University of Agriculture in Nitra, Faculty of European Studies and Regional Development, Department of Ecology, Mariánska 10, 94901 Nitra, phone: +421 37 6415615, e-mail: zuzana. jurekova@uniag.sk 